\title{
On the age of self-sufficiency in Scandinavian brown bears
}

\author{
Jon E. SWENSON, Robert FRANZÉN, \\ Peter SEGERSTRÖM, and Finn SANDEGREN
}

\begin{abstract}
Swenson J. E., Franzén R., Segerström P., and Sandegren F. 1998. On the age of self-sufficiency in Scandinavian brown bears. Acta Theriologica 43: 213-218.

The young of brown bears Ursus arctos Linneaus, 1758 are sometimes orphaned and found by humans. People and authorities often want to help these young survive by taking them into captivity. We report on the fate of five young-of-the-year brown bears in two litters that lost their mothers in May and September. We left food for one of the two cubs that were abandoned in May after the other one had died. $\mathrm{He}$ was shot four years later and had a normal weight at that time. The other three lost their mother in September, probably to illegal hunting. One was lighter than normal the following May and died that year. The two others are still alive at almost six years of age, and have shown normal growth and reproduction. We conclude that young-of-the-year brown bear cubs in Scandinavia can survive well on their own from the beginning of July, and recommend that they be left where they are found.

Norwegian Institute for Nature Research, Tungasletta 2, N-7005 Trondheim, Norway, e-mail: jon.swenson@ninatrd.ninaniku.no (JES); Swedish Environmental Protection Agency, S-106 48 Stockholm, Sweden (RF); Department of Animal Ecology, Swedish University of Agricultural Sciences, Pl 617, Vaikijaur, S-962 99 Jokkmokk, Sweden (PS); Research Division, Swedish Hunters' Association, Bäcklösavägen 8, S-756 51 Uppsala, Sweden (FS)
\end{abstract}

Key words: Ursus arctos, self-sufficiency, orphaned young, Sweden

\section{Introduction}

In many countries, female brown bears Ursus arctos Linneaus, 1758 are protected from hunting while accompanied by dependent young. However, occasionally females are killed while with young. An often emotional question frequently arises about the fate of orphaned young-of-the-year; should they be left to themselves or should they be taken into captivity?

This question has been studied in detail in the American black bear Ursus americanus Pallas, 1780, with the conclusion that orphaned young can survive on their own, even from as early as five months of age (Erickson 1959, Payne 1975, Alt and Beecham 1984). However, black bears usually separate from their mothers in the spring as yearlings (Rogers 1987). The period of maternal care is often longer in brown bears; the young leave at ages varying from one to four years (Camarra 1989, McLellan 1994), which suggests that brown bear cubs may need their mothers for a longer time than black bear cubs. 
Studies of brown bear cubs that have been in captivity before being released showed that the cubs were able to survive on their own from July and September (Jonkel et al. 1980, Pazhentov 1990 and pers. comm.). We have located four reports about completely wild brown bear cubs. Johnson and LeRoux (1973) marked, moved, and released a male cub that was orphaned in August in Alaska, USA. It was shot one year later $77 \mathrm{~km}$ away, but no weight was available. Russell et al. (1979) reported that 3 unmarked cubs that had lost their mother in late July were all still alive at least until the following July in Alberta, Canada. Palomero et al. (1992) followed 3 unmarked cubs that apparently lost their mother in July in Spain. They denned together and were observed together until May the following year. Craighead et al. (1995), however, found that, of 21 orphaned cubs in 9 litters in a population associated with garbage dumps in Yellowstone National Park, USA, 7 survived to at least one year of age, 7 died or were sent to zoos before becoming one year old, and 7 were unaccounted for. Only one of these orphans was known to survive beyond yearling age; it reached adult age. Thus, the literature suggests that brown bear cubs are self-sufficient from July in some, but not all, areas. Also, little is know about the condition or survival of orphaned cubs over a longer time period. Here we report the survival and growth of 5 brown bear cubs orphaned from two litters in northern Sweden, where about half of the young separate naturally as yearlings and the other half as two-year-olds, which is earlier than for North American brown bears.

\section{Study area and methods}

The study area was northwest of Jokkmokk in the southwestern part of Norrbotten, the northernmost county in Sweden $\left(67^{\circ} \mathrm{N}, 18^{\circ} \mathrm{E}\right)$. The area is rolling with elevations below $300 \mathrm{~m}$ in the east, but is dominated by mountains that rise to over $2000 \mathrm{~m}$ in the west. Glaciated U-shaped valleys are common. The northern boreal forest is dominated by Scots pine Pinus sylvestris and Norway spruce Picea abies, but there are extensive subalpine forests dominated by birch Betula spp. (Bjärvall and Sandegren 1987).

Three yearling brown bears were captured in the spring by shooting them from a helicopter with darts containing immobilizing drugs. Two young-of-the-year cubs were captured at the den site after being abandoned, as described below. Captured bears were weighed on a spring scale to the nearest $1 \mathrm{~kg}$ and an identifying number was tattooed on the inner side of the lip. Bears received radio transmitters, mounted on a collar or attached to an ear (Bjärvall and Sandegren 1987) and they were located about once a week during their active period.

Young bears were captured each spring to change collars and obtain weights. We compared their spring weights with others of the same age and sex in the study area (Scandinavian Brown Bear Research Project, unpubl. data). We compared the weight of the male killed during the hunting season with those of other males of the same age killed during the hunting season in the two northernmost counties in Sweden (Västerbotten and Norrbotten). Ages were estimated from counting the annuli in the roots of a premolar tooth (Craighead et al. 1970). These weights and teeth were obtained from the mandatory reports on hunter-killed bears (Scandinavian Brown Bear Research Project, unpubl. data).

We also present the survival rates of radio-marked bears during 1985-1996, using the Kaplin-Meier technique (Kaplin and Meier 1958). We multiplied survival rates for each age class to obtain survival rates for periods longer than a year. When this was done, the sample size is given as 
"bear-years", ie the sum of the number of bears followed in each of the age classes in question. When calculating mortality rates, we considered a sudden stopping of a transmitter during the spring, when there was enough snow for snowmobile travel, or during the autumn moose Alces alces hunting season, to be an illegal mortality. No bears classified as "probably killed illegally" by this criterion have been recaptured subsequently nor killed in a subsequent hunting season in this area. Cub survival was based on observed, but unmarked, cubs accompanying radio-marked females. Cub survival is high (98\%) in this area (Swenson et al. 1997).

\section{Results}

A radio-marked eight-year-old female brown bear (BD10) gave birth to two young in 1989, about $30 \mathrm{~km}$ from Jokkmokk. She was at the den on 19 April and 2 May. On 5 May, a set of tracks leaving the den area was observed from a helicopter, but no radio-telemetry equipment was in the helicopter at the time. On 6 May, radio-telemetry confirmed that she had left the den. On 9 May, she was observed from an airplane without young about $5 \mathrm{~km}$ from the den.

The den was visited on 20 May, and male and female cubs were found in the top of a 15-m Norway spruce. The female was caught and marked with a radio transmitter mounted on a neck collar. On 4 June, the female cub was found dead, probably due to starvation, and the male (BD26) was marked with an ear-mounted radio transmitter. At this time, we decided to give food to the surviving cub. Dog food («Frolic») was used primarily, but also slaughterhouse scraps, frozen berries, fish, honey, etc. were placed a few hundred meters from the den opening at regular intervals. The male cub was not seen again, but all the food disappeared and he stayed close to the den until around 19 June, when he moved $1 \mathrm{~km}$ away. He returned occasionally, but spent more and more time away. On 8 August, he lost his transmitter.

Local people observed a small bear in this area that summer and in following summers. From this, the local opinion was that the bear survived, but remained small. However, BD26 was shot legally on 10 September 1993 about $60 \mathrm{~km}$ from his place of birth. His live weight was calculated to be about $181 \mathrm{~kg}$, based on a slaughter weight of $120 \mathrm{~kg}$ and the regression formula of Swenson et al. (1995). In comparison, the mean live weight of eight other four-year-old male brown bears killed in northernmost Sweden during the autumn was $173.6 \pm 30.5$ (SD) kg. Based on following radio-marked males and cubs of radio-marked females in this population, we have found that the probability of surviving from spring as a cub to autumn as a four-year-old for males is 0.46 ( $n=112$ bear-years).

In 1991, a radio-marked 14-year-old female (BD27) had three cubs. She disappeared suddenly during the hunting season in September 1991, with circumstances suggesting that she had been killed illegally. On 6 May 1992, three yearlings were observed together at their den site, about $3 \mathrm{~km}$ from where BD27 was last located and within her former home range. In our study, all cubs with radio-marked mothers have entered the den with their mothers and emerged with her as yearlings. However, in this case, the cubs had wintered without their 
Table 1. Spring body weights (in $\mathrm{kg}$ ), of three orphaned brown bears in northern Sweden, compared with the mean spring weights of radio-marked bears of the same age and sex in the same area (mean is given with standard deviation, sample size in parentheses).

\begin{tabular}{lccccc}
\hline $\begin{array}{l}\text { Age, } \\
\text { in years }\end{array}$ & $\begin{array}{c}\text { Female } \\
\text { BD37 }\end{array}$ & $\begin{array}{c}\text { Mean for } \\
\text { females }\end{array}$ & $\begin{array}{c}\text { Male } \\
\text { BD38 }\end{array}$ & $\begin{array}{c}\text { Male } \\
\text { BD39 }\end{array}$ & $\begin{array}{c}\text { Mean for } \\
\text { males }\end{array}$ \\
\hline 1 & 25 & $23.7 \pm 4.3(22)$ & 30 & 20 & $30.8 \pm 9.6(17)$ \\
2 & 45 & $44.1 \pm 13.0(17)$ & 64 & - & $60.9 \pm 16.2(19)$ \\
3 & 83 & $72.7 \pm 16.0(12)$ & 96 & - & $114.1 \pm 44.9(12)$ \\
4 & 98 & $89.4 \pm 7.4(9)$ & 112 & - & $117.2 \pm 30.0(8)$ \\
5 & & & 169 & - & $145.6 \pm 23.4(5)$ \\
\hline
\end{tabular}

mother, because there were only three bed sites in the den. Thus, we conclude that they were BD27's orphans. They were all captured and radio-marked; one female (BD37) and two males (BD38 and BD39). The male (BD39) died in July 1992 of unknown causes. He was smaller than average for a yearling male in the spring, although within one standard deviation of the mean (Table 1). The survival of radio-marked yearling males in this population is $0.88(n=17)$. The other male (BD38) is still alive as of winter 1996/97. Based on radio-marked males in this population, we have found that the survival rate from spring as a yearling to autumn as a five-year-old is 0.31 ( $n=69$ bear-years). His growth has been similar to that of other radio-marked males in this population (Table 1).

The female (BD37) was still alive as of winter 1996/97 and her growth was similar to that of other females in the population (Table 1). In spring 1996, when BD37 was five years old, she was accompanied by three cubs and was therefore not captured for remarking. All the cubs survived the summer and entered the den with her in the autumn. In this population, the mean age of successful reproduction is $5.3 \pm 0.5$ years $(n=9)$, and $78 \%$ are first successful mothers at the age of five years. No births to four-year-old females have been observed ( $n=9$ ). The average litter size is $2.4 \pm 0.8(n=23)$ (Scandinavian Brown Bear Research Project, unpub.). Based on radio-marked females in this population, the probability of surviving from spring as a yearling to autumn as a five-year-old is $0.73(n=$ 69 bear-years).

\section{Discussion}

Although we have only followed five orphaned cubs from two litters, including the one that died at the den shortly after being abandoned, we are apparently the first to report growth rates of orphaned brown bear cubs and among the first to report their survival over several years. Our results showed that the cubs survived well without their mothers from about midsummer. Only one of the orphans did not reach the age of 4 years, and it is possible that becoming an orphan reduced 
his survival, because yearling males have a relatively high survival rate in this population. He was unusually small in the spring of his yearling year. Among the three orphans that survived beyond their yearling year, we could not document that loosing the mother had a negative effect on subsequent growth or survival. The other orphan was killed by a hunter and had reached the age of four years, in spite of a high mortality for males to that age.

This raises an important question of why some young stay with their mother until they are two years old when they obviously can survive well as yearlings, or even before. The mother provides learning, protection, and energetic advantages during denning in winter, all obvious benefits to the young. But, if the mother keeps them with her as two-year-olds, she must delay reproduction by one year. That some mothers keep their young for the extra year implies that there is a trade-off involved, and that the two-year-olds obtain an added advantage of staying with the mother. This was shown by Craighead et al. (1995), who found that young weaned as yearlings were five times more likely to die than those weaned later in Yellowstone National Park, where bears were concentrated at garbage dumps. Orphaned cubs and weaned yearlings may be especially vulnerable in such concentrations of bears. It is possible that orphaned cubs and weaned yearlings have a higher survival in our study population, which is increasing after an earlier reduction (Swenson et al. 1994) than would be the case at densities nearer carrying capacity. We are continuing our studies and hopefully will be able to answer this question for this population in the future.

Our results are important for the fate of lone cubs that are found in Scandinavia. Our results, and those of the literature, show that the chances of survival, normal growth, and reproduction of orphaned cubs are high enough that it is ethically responsible to leave the cubs to fend for themselves. We recommend that all cubs orphaned from the beginning of July be left where they are found. This applies to all of Scandinavia, because farther south in Sweden young usually leave their mothers as yearlings (Scandinavian Brown Bear Project, unpubl.). However, if the orphaned cubs are near human habitation, they should be moved away and released, because Alt and Beecham (1984) found that orphaned black bear cubs had a propensity to visit human habitation looking for food.

Acknowledgments: We thank E. Nilsson for help in catching the cubs at the den, and for putting food out for BD26 until he left the den area. This study has been supported financially by the Swedish Environmental Protection Agency, the Swedish Hunters' Association, Norwegian Institute for Nature Research, Norwegian Directorate for Nature Management, WWF-Sweden, Norrbotten County Government, and Volvo.

\section{References}

Alt G. L. and Beecham J. J. 1984. Reintroduction of orphaned black bear cubs into the wild. Wildlife Society Bulletin 12: 169-174.

Bjärvall A. and Sandegren F. 1987. Early experiences with the first radio-marked brown bears in Sweden. Proceedings of the International Conference on Bear Research and Management 7: 9-12. 
Camarra J. J. 1989. L’ours brun. Hatier, Paris: 1-213.

Craighead J. J., Craighead F. C., Jr and McCutchen H. E. 1970. Age determination of grizzly bears from fourth premolar tooth sections. Journal of Wildlife Management 34: 353-363.

Craighead J. J., Sumner J. S. and Mitchell J. A. 1995. The grizzly bears of Yellowstone, their ecology in the Yellowstone Ecosystem, 1959-1992. Island Press, Washington, D. C.: 1-535.

Erickson A. W. 1959. The age of self-sufficiency in the black bear. Journal of Wildlife Management 23: 401-405.

Johnson L. J. and LeRoux P. 1973. Age of self-sufficiency in brown/grizzly bear in Alaska. Journal of Wildlife Management 37: 122-123.

Jonkel C. J., Husby P., Russell R. and Beecham J. 1980. The reintroduction of orphaned grizzly bear cubs into the wild. Proceedings of the International Conference on Bear Research and Management 4: 369-372.

Kaplin E. L. and Meier P. 1958. Nonparametric estimation from incomplete observations. Journal of the American Statistics Association 53: 457-481.

McLellan B. 1994. Density-dependent population regulation of brown bears. Ninth International Conference on Bear Research and Management, Monograph Series No. 3: 15-24.

Palomero G., Blanco J. C., García P. and Palomero G. 1992. Ecology and behaviour of 3 wild orphaned brown bear cubs in Spain. [In: Management and restoration of small and relictual bears populations, F. Bourliere, President of the Scientific Committee]. Museum d'Historie Naturelle, Grenoble: 194-204.

Payne N. F. 1975. Unusual movements of Newfoundland black bears. Journal of Wildlife Management 29: $812-813$.

Pazhentov V. S. 1990. [The brown bear]. Agropromizdat, Moscow: 1-214. [In Russian]

Rogers L. L. 1987. Effects of food supply and kinship on social behavior, movements, and population growth of black bears in northeastern Minnesota. Wildlife Monographs 97: 1-72.

Russell R. H., Nolan J. W., Woody N. A. and Anderson G. 1979. A study of the grizzly bear (Ursus arctos L.) in Jasper National Park, 1975-1978, final report. Unpublished report, Canadian Wildlife Service, Edmonton, Alberta: 1-136.

Swenson J. E., Sandegren F., Bjärvall A., Söderberg A., Wabakken P. and Franzén R. 1994. Size, trend, distribution and conservation of the brown bear Ursus arctos population in Sweden. Biological Conservation 70: 9-17.

Swenson J. E., Sandegren F., Söderberg A., Bjärvall A. and Franzén R. 1997. Infanticide caused by hunting of male bears. Nature 386: 450-451.

Swenson J. E., Sandegren F., Söderberg A. and Franzén R. 1995. Estimating the total weight of Scandinavian brown bears Ursus arctos from field-dressed and slaughter weights. Wildlife Biology 1: $177-179$.

Received 25 March 1997, accepted 18 September 1997. 